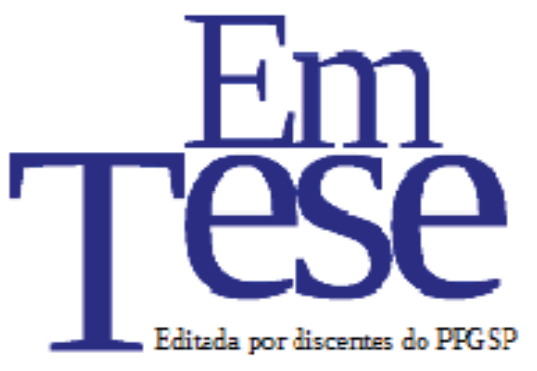

UFSC

PPG SP PROGRAMA DE

PÓS-GRADUAÇÃO EM

Sociologia

Política

\title{
O acesso à propaganda eleitoral televisionada nos municípios paulistas
}

\begin{abstract}
Mércia Alves ${ }^{1}$
Resumo: As campanhas eleitorais são importantes instituições nas democracias representativas, centrais na relação entre os partidos políticos que disputam cargos eletivos e eleitorado. Hoje, os meios de comunicação de massa, principalmente a televisão, cumprem um papel essencial durante os períodos eleitorais. Nessa direção, no Brasil o Horário Gratuito de Propaganda Eleitoral (HGPE) é por excelência o palco da política eleitoral mediada, meio pelo qual os partidos e candidatos apresentam propostas de governo, constroem a sua imagem pública e conferem ataques aos seus adversários. Entretanto, quando se trata das eleições municipais, na maioria das cidades os partidos não têm acesso ao HGPE, essas fazem parte da área de cobertura de outros municípios maiores. Buscando contribuir para o debate entre comunicação e política, este artigo tem como principal objetivo, indicar o mapa do acesso à propaganda eleitoral no estado de São Paulo. Questiona-se qual a amplitude da propaganda eleitoral no estado de São Paulo quanto ao alcance do eleitorado.
\end{abstract}

Palavras-Chave: Campanhas eleitorais; Eleições municipais; HGPE.

\section{Access to televised electoral propaganda in the municipalities of São Paulo}

Abstract: Electoral campaigns are important institutions in representative democracies, central to the relationship between political parties competing for elected office and electorate. Today, the mass media, especially television, play an essential role during election periods. In this direction, in Brazil, Free Election Propaganda Schedule (HGPE) is par excellence the stage of mediated electoral politics, through which parties and candidates present government proposals, build their public image and attack their opponents. However, when it comes to municipal elections, in most cities the parties do not have access to HGPE, they are part of the coverage area of other larger municipalities. Seeking to contribute to the debate between communication and politics, this article has as main objective, to indicate the map of the access to electoral propaganda in the state of São Paulo. It is questioned the amplitude of the electoral propaganda in the state of São Paulo regarding the reach of the electorate.

Keywords: Electoral campaigns; Municipal elections; Free Election Propaganda Schedule (HGPE).

\footnotetext{
1 Doutoranda em Ciência Política (PPGPOL/UFSCar); membro do grupo de pesquisa Comunicação Política, Partidos e Eleições da UFSCar. Bolsista da Fundação de Amparo à Pesquisa do Estado de São Paulo (FAPESP). E-mail: mercia_f.alves@hotmail.com.
} 


\section{Introdução}

As eleições são períodos nos quais é intensificada a relação entre partidos políticos, candidatos, cidadãos comuns e meios de comunicação. Nesse sentido, as campanhas assumem o protagonismo do processo eleitoral, uma vez que ampliam o debate público, conferem visibilidade, legitimam as candidaturas e tornam públicas as agendas. As campanhas mediadas pelo rádio e, principalmente, pela televisão, também são responsáveis pela percepção do cidadão comum do momento de exercer o papel de eleitor.

A utilização intensiva da televisão como principal recurso eleitoral é uma das principais variáveis do processo de modernização das campanhas eleitorais, fenômeno político característico das sociedades midiáticas, onde o cidadão, que se torna eleitor, se converte também em audiência (MANIN, 1995; SWANSON e MANCINI, 1996). Assim, a exploração instrumental da TV e a adequação do discurso político à sua linguagem é parte fundamental do processo de organização das campanhas, quando se tem por objetivo a mínima eficiência eleitoral.

Quando se trata de eleições municipais, há basicamente duas formas de se organizar campanhas. A primeira é a partir da televisão como principal ponte entre candidato e eleitor; e a segunda sem esse recurso, uma vez que na maioria dos municípios brasileiros os partidos políticos não têm acesso à propaganda eleitoral televisionada. Isso porque poucas cidades possuem emissoras geradoras concessionadas, nessas os partidos têm a possibilidade de veicular propaganda eleitoral para prefeito e vereador. Nos municípios vizinhos, aqueles que não possuem, os eleitores assistem pela TV à propaganda das emissoras geradoras que os atingem.

Este artigo tem como principal objetivo indicar o mapa da propaganda eleitoral no estado de São Paulo. Isto é, apontar quais são os municípios paulistas sede de emissoras geradoras concessionadas de televisão e que, por isso, disponibilizam às organizações partidárias locais a possibilidade de veicular a propaganda eleitoral. Não apenas quais os municípios, mas qual o perfil desses e das suas respectivas áreas de cobertura, atentando principalmente para indicadores como população e colégio eleitoral. Questiona-se qual a amplitude da propaganda eleitoral no estado de São Paulo quanto ao alcance do eleitorado.

Este trabalho está inserido na linha de pesquisa sobre comunicação política e eleições, com ênfase na centralidade dos meios de comunicação de massa nos processos 
eleitorais e busca contribuir para o debate sobre as campanhas municipais, uma lacuna na ciência política brasileira, a qual se deve a falta evidências consistentes sobre aspectos específicos das eleições nos municípios, principalmente fora do eixo das capitais dos estados e das grandes cidades.

\section{Campanhas, centralidade da TV e o uso instrumental do HGPE}

As mudanças nas campanhas eleitorais identificadas nas democracias ocidentais nas últimas décadas apresentam características semelhantes, apesar de se desenvolverem de formas muito particulares. Em linhas gerais, esse fenômeno tem como variáveis, segundo Manin (2013), o enfraquecimento dos laços partidários e a ressignificação do papel dos partidos políticos quanto à sua atuação na arena eleitoral, a centralidade dos meios de comunicação de massa durante as campanhas e o declínio do debate ideológico e crescente personalização da política.

Os meios de comunicação, principalmente a TV, ao conferirem visibilidade pública aos atores políticos, tornam as campanhas eleitorais, campanhas de massa. $\mathrm{Ou}$ seja, o discurso ora voltado a um público muito específico, presente nos comícios locais, com forte teor ideológico, quando transportado para TV assume um caráter mais homogêneo. O que exige dos partidos a adaptação a adaptação das estratégias de campanha para atrair o eleitorado (MANCINI e SWANSON, 1996).

A utilização da TV nas campanhas eleitorais modernas é instrumental, no sentido de que a comunicação passa a ser persuasiva, dirigida especificamente para a conquista do voto (MAZZOLENI, 2010), não necessariamente para criar vínculos baseados na fidelidade partidária, mas para a obtenção de informação política, que nesse contexto, dispensa qualquer tipo de interação direta entre partido político e eleitor (MANIN, 1995). Em suma, a centralidade da TV e recente, o uso de novas ferramentas, como as novas tecnologias de informação (NORRIS, 2000), modificam a forma de como partidos organizam suas campanhas.

Nesse sentido, o uso de pesquisas de opinião pautam as principais estratégias de comunicação campanhas, a dependência de profissionais especializados para condução dessas estratégias, em detrimento do trabalho voluntário desempenhado pela militância, são elementos que tornam a gestão dessas campanhas mais complexas, elevam o seu custo e o tempo dedicado pelas elites partidárias à sua organização (FARREL, 2009). Além disso, a adequação do discurso à lógica da TV e a adesão de elementos 
publicitários, tornam os processos eleitorais mais personalizados, voltados à lógica da construção da imagem do candidato (MANIN, 2013).

Segundo Canel (1999), a propaganda eleitoral televisionada produz efeitos sobre o comportamento e as atitudes dos eleitores, primeiro porque contém informação política e, de alguma forma discute temas e questões de interesse público. Segundo, que ao utilizar elementos de publicidade, são mais eficazes em fixar a sua mensagem, seja essa uma proposta específica, ou apenas o nome e número do candidato, além dos elementos que compõe a construção da sua imagem, ou ainda a imagem desconstruída dos adversários. Finalmente, porque a agenda da propaganda eleitoral influi na agenda de outros meios.

A modernização das campanhas no Brasil teve como marco histórico as eleições de 1989, quando atores políticos passaram a olhar para o potencial da TV como instrumento eleitoral. A expansão quantitativa dos meios de comunicação (RUBIM, 2001), e a importância da TV como principal fonte de informação e entretenimento para o brasileiro (AZEVEDO, 2006), foram fatores de importância para a consolidação do processo de modernização das campanhas nos pleitos seguintes. Assim, em períodos eleitorais a centralidade da TV é acentuada de forma que ela torna o "locus" das campanhas (ALBUQUERQUE, 1999), exercendo uma influência decisiva nos resultados eleitorais (BORBA, 2008).

No Brasil o acesso à TV em períodos eleitorais é garantido pelo Estado aos partidos, diferente do caso norte americano, no qual o modelo brasileiro é baseado, onde os partidos e candidatos pagam pelo espaço das emissoras de TV, assim como a publicidade comercial. Segundo Albuquerque (1997), o modelo de propaganda brasileira tem dois elementos que lhe são próprios: a sua natureza educativa e não comercial; e a identificação dos partidos como "agentes", uma vez que a eles pertence o acesso e o tempo de TV, além do monopólio da representação.

O $\mathrm{HGPE}^{2}$, nesse sentido, é o principal palco das campanhas, por onde as candidaturas tornam-se públicas, as informações políticas são sintetizadas e candidato e eleitor podem estabelecer uma relação mínima de credibilidade (VEIGA, 2002). Segundo Albuquerque (1999), os programas são compostos por pequenos blocos de cenas e mensagens de cumprem papeis distintos: discutir temas de campanha, propostas e possíveis soluções para problemas determinados; construir a imagem do candidato e

\footnotetext{
${ }^{2}$ Horário Gratuito de Propaganda Eleitoral.
} 
desconstruir o adversário; informar o eleitor sobre o andamento e chamá-lo a engajar-se; além da pedagogia do voto, quando se ensina a votar.

O modelo da propaganda eleitoral televisionada, que compreende o HGPE e os spots $^{3}$, reforça o caráter personalista das campanhas eleitorais brasileiras (AZEVEDO, 2001), ou seja, a centralidade da imagem pessoal do candidato. Além disso, os apelos emocionais, jingles e slogans, são elementos próprios da propaganda comercial, levados à esfera política por experts (AZEVEDO, 2001; RIBEIRO, 2004; LIMA, 2008), encarregados de utilizar o recurso da TV de forma instrumental, ou seja, visando eficiência eleitoral, principal objetivo de partidos políticos competitivos (AZEVEDO, 1998).

O formato do HGPE representa um desafio para os partidos (ALBUQUERQUE, 1997), que devem adaptar as suas estratégias de comunicação à delimitação de tempo disponível, e mobilizar recursos financeiros suficientes para a produção do conteúdo, processo encarecido devido aos fatores citados. Esses são argumentos importantes para o objetivo deste trabalho, que é compreender aspectos específicos relativos às campanhas eleitorais nos municípios brasileiros, principalmente fora das capitais.

Primeiro, porque na maioria das cidades brasileiras os partidos não têm acesso à propaganda eleitoral televisionada. Segundo, porque onde este recurso está disponível, os partidos tem mais minutos de propaganda, se comparados às eleições para os demais cargos executivos. Isso, devido ao número reduzido de cargos em disputa: prefeito e vereador, ao passo que em eleições gerais, são quatro ${ }^{4}$. Com mais tempo, os partidos e candidatos locais naturalmente arrecadam um montante de dinheiro menor para financiamento das suas atividades de campanha.

A modernização e profissionalização das campanhas eleitorais brasileiras são conceitos dos quais partem a maioria das pesquisas que investigam a relação entre meios de comunicação e atores políticos nos processos eleitorais. É ponto pacífico a importância da TV como principal variável desses fenômenos e a sua importância para as campanhas contemporâneas. Entretanto, uma questão importante quando o objeto de estudo são as campanhas locais é: como os partidos organizam as suas campanhas sem o recurso da TV?

\footnotetext{
${ }^{3}$ Desde as eleições municipais de 1996 os partidos têm acesso a TV também por meio dos spots. Comerciais de 30 ou 60 segundos inseridos na programação normal das emissoras abertas. Diferente do HGPE, esses comerciais pegam de surpresa os espectadores, uma vez que não tem um horário fixo de exibição.

${ }^{4}$ Nas eleições gerais brasileiras são disputados os cargos de deputado estadual e federal, senador (ou senadores), governo do estado e presidência da república.
} 
No entanto, a questão a ser respondida neste trabalho é anterior a essa: em quais dos municípios, especificamente no estado de São Paulo, os partidos políticos e candidatos têm acesso à propaganda eleitoral televisionada? O número de eleitores contemplados é abrangente? É possível afirmar que a TV é um recurso importante nas eleições para prefeito, tanto quanto em eleições gerais, quando todos os eleitores brasileiros podem, por meio do HGPE e dos spots, ter acesso a essa fonte de informação política e eleitoral.

\section{Campanhas eleitorais nos municípios}

Embora crescente nos últimos anos, existe uma desproporcionalidade nos estudos de eleições majoritárias no Brasil. Isso porque há uma clara concentração em relação às eleições à presidência da república e aos governos estaduais. Quando se trata de eleições municipais, a ênfase está nas capitais brasileiras. Esse é um dos fatores que contribui para a falta de evidências consistentes sobre aspectos específicos das eleições nos municípios do interior dos estados, principalmente sobre as suas campanhas eleitorais e a relação com os meios de comunicação.

A capital paulista é uma privilegiada. Entre alguns dos principais estudos sobre as campanhas eleitorais em São Paulo, está o trabalho de Porto (1995), que analisa os efeitos dos meios de comunicação de massa, principalmente da TV, e a influência desses no voto para eleições de 1992; os spots como elemento surpresa nas eleições municipais de 1996, a primeira a contar com esse recurso (ALDÉ e DIAS, 1997) e as estratégias utilizadas na propaganda eleitoral na campanha à prefeitura no mesmo ano (FIGUEIREDO, ALDÉ, DIAS e JORGE; 1997); a cobertura eleitoral da imprensa durante as eleições municipais de 2000 (AZEVEDO, 2001); o discurso eleitoral e estratégias retóricas a partir do HGPE e dos spots das eleições municipais em 2004 (VEIGA, SOUZA e CERVI, 2007).

Estão entre os trabalhos que contribuem para os estudos de eleições locais recentemente, o livro organizado por Lavareda e Telles (2011), que traz evidências importantes sobre campanha e voto em 12 capitais brasileiras nas eleições municipais de 2008; outra organização publicada pelos mesmos autores, sobre lógica das eleições em municipais (2016); e a coletânea a respeito do uso do HGPE nas disputas das capitais em 2012, editada por Cervi e Panke (2013). Nesses trabalhos, a relação entre eleições e meios de comunicação é abordada a partir da TV, em especial o uso do HGPE e dos 
spots, do rádio, e da campanha online, principalmente o Facebook e o Twitter, além da cobertura da imprensa durante as eleições.

Segundo Jardim (2004) há basicamente duas formas de se organizar campanhas eleitorais nos municípios brasileiros, a primeira forma, a partir do recurso da televisão, as campanhas eletrônicas e, a segunda, onde não há o recurso da TV e consequentemente o HGPE, campanhas denominadas tradicionais pela autora. Entretanto, para que uma campanha eleitoral seja classificada como tradicional, além da falta do intermédio da TV, é necessário identificar práticas típicas das campanhas tradicionais.

Essas campanhas são caracterizadas principalmente, pela realização de comícios e atividades que priorizam o contato direto entre candidato e eleitor. Além de uma organização e discurso centrado na lógica partidária, com pouca antecedência (MAZZOLENI, 2010), onde as atividades de comunicação e divulgação são realizadas principalmente pela militância voluntária, e não por pessoal especializado, contratado a partir de uma formação específica. Ou seja, para além da ausência da propaganda na TV. Além disso, o acesso ao HGPE não garante que os partidos farão seu uso de forma instrumental.

Aqui, o argumento central é que para eleições municipais, há sim duas formas de se organizar campanhas: com e sem acesso ao HGPE. Nos municípios onde há propaganda eleitoral televisionada, primeiro, como aponta Dantas (2012), os partidos podem acordar em renunciá-lo devido ao seu alto custo de produção. $\mathrm{O}$ alto custo também pode ser um obstáculo para o uso instrumental da TV, uma vez que campanhas municipais, principalmente do interior, tendem a arrecadar menos recursos para financiamento de suas atividades de campanha. Ou seja, o acesso ao HGPE não significa que a campanhas eleitorais sejam organizadas de forma profissional.

Seguindo a mesma lógica, a ausência do acesso à propaganda eleitoral na TV, não significa necessariamente que as campanhas assumam um carácter tradicional, porque as atividades que são centrais para essa definição, tais como os comícios e carreatas, são práticas que cada vez mais estão em desuso pelos partidos para campanhas locais, principalmente em cidades de médio e grande porte. Isso, pela dificuldade em atrair eleitores, principalmente depois da proibição de atrações musicais e de entretenimento ${ }^{5}$, os populares "showmícios". Quando ocorrem esses tipos de

\footnotetext{
${ }^{5}$ Lei 11.300/06.
} 
eventos, esses têm entre as finalidades a realização de cenas para a TV e levam às ruas pessoal contratado, ou que tem alguma relação com determinado partido e/ou candidato.

Além disso, a internet como espaço de campanha tem sido um importante objeto de análise nos últimos anos. Apesar de ainda existirem dificuldades na exploração dos potenciais das campanhas online durante o período eleitoral (PENTEADO, 2012), a sua importância hoje é inquestionável, uma vez que os websites e, principalmente, as redes sociais têm se desenvolvido nos últimos pleitos como uma parte significativa para as campanhas, utilizadas cada vez mais por partidos e candidatos, para compartilhamento de informação política (BRAGA, NICOLÁS e BECHER, 2013; IASULAITIS, 2008; 2013), como meio de engajamento e participação (GOMES, 2001) e de apoio a determinado partido e candidato (MASSUCHIN e CAMPOS-DOMINGUEZ, 2016).

Nas cidades onde não há acesso à propaganda eleitoral televisionada, as novas tecnologias de informação, os websites e as páginas nas redes sociais podem significar, para os partidos e candidatos, meios de tornar publicas suas campanhas, ainda que essas contem com recursos financeiros limitados. A partir de uma pesquisa desenvolvida em uma cidade do interior paulista, Alves (2015) demonstrou que candidatos, mesmo com acesso à TV, porém com pouco tempo disponível e poucos recursos financeiros, mantiveram em suas redes sociais durante as eleições de 2012, as suas principais plataformas de campanha. Ressalvas feitas aos limites de acesso à internet e ao processo de adaptação dos partidos e da legislação brasileira às campanhas online, esses podem ser considerados fortes indícios das tendências para eleições futuras, inclusive para discussão dos conceitos de modernização e profissionalização.

\section{O acesso à propaganda eleitoral televisionada nos municípios}

A propaganda eleitoral brasileira, tal como conhecemos hoje, é regida pela Lei $\mathrm{n}^{\circ}$ 9.504/1997, onde foram determinados os princípios fundamentais das campanhas no Brasil, como a instituição do HGPE. Alterações depois, as características fundamentais se mantêm: o acesso gratuito aos meios de comunicação às coligações partidárias, com a divisão de tempo baseada no tamanho das bancadas dos partidos ${ }^{6}$. Para cada eleição,

\footnotetext{
${ }^{6}$ Para as eleições de 2016, o tempo de propaganda eleitoral diminuiu, sendo dois blocos de 10 minutos no rádio e na televisão. Na TV o HGPE é exibido das 13 h00 às 13 h10 e das 20h30 às 20h40, de segundafeira a sábado. Onde, $90 \%$ do tempo de propaganda é distribuído conforme o número de representantes na Câmera dos Deputados, e 10\% igualmente. Os partidos também terão direito, nos municípios sede de
} 
uma resolução do TSE dispõe suas as especificidades, inclusive em relação à propaganda eleitoral.

Para o pleito de 2016 a Resolução No 23.457 estabelece, baseada na Reforma Eleitoral de 2015, que a transmissão da propagada veiculada pelo HGPE deve ser assegurada nos municípios com emissoras de rádio e TV que operam em VHF e $\mathrm{UHF}^{7}$, e onde há estação geradora. Nos municípios que contam com mais de 200 mil eleitores, ou seja, com possibilidade de segundo turno, onde não há emissora ou estação geradora, a justiça eleitoral deverá garantir a veiculação da propaganda a partir dos municípios aptos, uma vez que viável.

Para assegurar o direito à propaganda eleitoral, os partidos devem se reunir junto aos representantes das TVs dos municípios onde há mais de uma emissora ou estação geradora $^{8}$, e à justiça eleitoral para tomar decisões sobre quem irá transmitir a propaganda de cada município requerente. A legislação também prevê o sorteio, em caso de falta de consenso, para elaboração do "plano de mídia", como determina o $\mathrm{TSE}^{9}$, a partir do dia 15 de agosto do ano eleitoral.

\subsection{O acesso à propaganda eleitoral nos municípios paulistas}

O presente trabalho propõe precisar o mapa da propaganda eleitoral no estado de São Paulo. Em resumo, para que os partidos políticos tenham acesso ao HGPE durante as eleições em seus respectivos municípios é necessário que esse seja sede de uma emissora geradora. Assim, para atender a esse objetivo, primeiro serão indicados quais são os municípios paulistas sede de emissoras geradoras próprias de televisão, as emissoras afiliadas, que retransmitem o conteúdo nacional, além do conteúdo local para determinadas regiões.

As emissoras geradoras são aquelas que geram conteúdo (UHF/VHF). No Brasil, as emissoras geradoras abertas são: TV Record, SBT, TV Globo, Bandeirantes, TV Gazeta, TV Cultura e RedeTV. Entre essas, as quatro primeiras contam com afiliadas espalhadas pelo estado de São Paulo, formando uma rede. A TV Gazeta tem concessão

emissoras geradoras ou retransmissoras, a 70 minutos diários de spots de 30 e 60 segundos, dos quais $60 \%$ para candidatos ao executivo e $40 \%$ para os candidatos ao legislativo, de segunda a domingo.

${ }^{7}$ Inclusive nos canais de televisão por assinatura que são responsabilidade das Câmeras Municipais. Essa modalidade não foi incluída neste trabalho, assim como as emissoras educativas locais, sob o argumento da baixa audiência desses canais.

${ }^{8}$ No caso de haver menos emissoras que o número de municípios onde a maioria dos partidos requer direito à propaganda, será utilizado o critério do número de eleitores.

${ }^{9}$ Lei n ${ }^{\circ}$ 9.504/1997, art. 52. 
apenas na capital paulista e transmite o mesmo conteúdo para as demais cidades, a TV Cultura possui uma afiliada na cidade de Araraquara, mas que reproduz a programação da sede na capital, e a RedeTV, sediada em Osasco, mas concessionada em São Paulo, não tem afiliadas no estado.

A primeira tabela apresenta os dados sobre a rede de afiliadas por emissora, no estado de São Paulo e a cidade sede de cada uma delas ${ }^{10}$. Em seguida, a população por cidade sede, o número de cidades que são parte das áreas de cobertura e a população correspondente. Como poderá ser observado, a Rede Globo é a emissora com maior número de filiadas no estado de São Paulo, por esta razão, a análise das regiões partirá dos dados dessa emissora. Por fim, a relação entre o colégio eleitoral das cidades com possibilidade de acesso à TV em contraponto aos maiores colégios eleitorais do estado.

${ }^{10}$ Para construção das tabelas sobre cidades sede e área de cobertura foram utilizadas as informações oficiais das emissoras de TV citadas, adquiridas a partir dos correspondentes atlas de cobertura, por email. 
Tabela 01: Exibidoras e cidades sede por emissora

\begin{tabular}{|c|c|c|}
\hline Emissora & Exibidora & Cidades sede \\
\hline \multirow{13}{*}{ Globo } & TV TEM Bauru & Bauru \\
\hline & EPTV Campinas & Campinas \\
\hline & TV TEM Itapetininga & Itapetininga \\
\hline & TV Diário & Mogi Das Cruzes \\
\hline & TV Fronteira & Presidente Prudente \\
\hline & EPTV Ribeirão Preto & Ribeirão Preto \\
\hline & TV Tribuna & Santos \\
\hline & EPTV Central & São Carlos \\
\hline & TV TEM SJ do Rio Preto & SJ do Rio Preto \\
\hline & TV Vanguarda & SJ dos Campos \\
\hline & TV Globo & São Paulo \\
\hline & TV TEM Sorocaba & Sorocaba \\
\hline & TV Vanguarda & Taubaté \\
\hline \multirow{7}{*}{ Band } & TV Band Campinas & Campinas \\
\hline & TV Band SP Interior & Presidente Prudente \\
\hline & TV Clube & Ribeirão Preto \\
\hline & TV Band Litoral & Santos \\
\hline & TV Band São Paulo & São Paulo \\
\hline & TV Band Vale & Taubaté \\
\hline & Band SAT & 11 \\
\hline \multirow{6}{*}{ Record } & Record Paulista & Bauru \\
\hline & TVB & Campinas \\
\hline & Record Interior & Franca \\
\hline & Record Rio Preto & SJ do Rio Preto \\
\hline & Record Litoral & Santos \\
\hline & Record & São Paulo \\
\hline \multirow{6}{*}{ SBT } & SBT Interior & Araçatuba \\
\hline & SBT Central & Jaú \\
\hline & SBT São Paulo & Osasco $^{12}$ \\
\hline & VTV & Santos \\
\hline & SBT RP & Ribeirão Preto \\
\hline & TV Sorocaba & Sorocaba \\
\hline
\end{tabular}

Fonte: Elaboração própria

Como pode ser observado na primeira tabela a Rede Globo é a emissora de TV que possui o maior número de afiliadas no estado de São Paulo. São 13 exibidoras sediadas nos municípios paulistas, enquanto as demais, Band, Record e SBT, estão em seis municípios. Em comum, todas as emissoras de TV aberta tem concessão na capital paulista $^{13}$, cidade de maior população e colégio eleitoral do Estado e do país. Além da

\footnotetext{
${ }^{11}$ A emissora não disponibiliza informações oficiais sobre a sede de concessão e a área de cobertura da Band SAT.

${ }^{12}$ Assim como no caso da RedeTV, SBT São Paulo é sediada na cidade de Osasco, porém concessionada na capital paulista.

${ }^{13}$ Além das emissoras que não possuem afiliadas, como já citado: TV Gazeta, TV Cultura e RedeTV.
} 
cidade de São Paulo, apenas Santos conta com uma afiliada das quatro emissoras, ou seja, são as cidades com maior número de concessões do Estado.

Uma vez que a Globo possui a maior rede de afiliadas no estado de São Paulo, serão utilizados os dados referentes a essa rede para análise das áreas de cobertura. As exceções serão as cidades de Araçatuba, Jaú e Franca, as únicas que contam com emissoras geradoras, porém, as duas primeiras ligadas ao SBT e a terceira à Record. Além da abrangência, a Globo é líder de audiência em todo o Brasil, inclusive no horário nobre da TV aberta ${ }^{14}$, quando é exibida a segunda sessão da propaganda eleitoral.

A segunda tabela apresenta a população ${ }^{15}$ de cada uma das cidades sede, a área de cobertura de cada uma das afiliadas Rede Globo, seguido pelo número de cidades que são parte dessas áreas de cobertura e a população de cada área. Para as três cidades citadas que são sede, porém de outras emissoras, serão utilizados os dados correspondentes.

\footnotetext{
${ }^{14} \mathrm{O}$ Horário Nobre da TV aberta compreende a programação exibida entre às $18 \mathrm{~h} 00$ e às $24 \mathrm{~h} 00$, com pico entre às $20 \mathrm{~h} 00$ e $22 \mathrm{~h} 00$, quando a audiência é maior. Segundo dados do IBOPE (2015), os programas mais assistidos pelos brasileiros nessa faixa de horário são duas novelas exibidas pela Rede Globo, o Jornal Nacional, o Fantástico e as transmissões esportivas às quartas-feiras, todos da mesma emissora, seguido por uma novela da Rede Record.

${ }^{15}$ População estimada, segundo dados do IBGE (2015).
} 
Tabela 02: População por cidades e área de cobertura

\begin{tabular}{|c|c|c|c|}
\hline \multirow{2}{*}{ Cidades } & \multirow{2}{*}{ População } & \multicolumn{2}{|c|}{ Área de cobertura } \\
\hline & & N de Cidades & População \\
\hline \multicolumn{4}{|c|}{ Afiliadas Globo } \\
\hline Bauru & 366.992 & 98 & 2.110 .474 \\
\hline Campinas & 1.164 .098 & 48 & 3.375 .678 \\
\hline Itapetininga & 157.016 & 49 & 1.069 .240 \\
\hline Mogi Das Cruzes & 424.633 & 9 & 1.163 .305 \\
\hline Presidente Prudente & 222.192 & 56 & 674.061 \\
\hline Ribeirão Preto & 666.323 & 65 & 1.898 .400 \\
\hline Santos & 433.966 & 26 & 1.692 .808 \\
\hline São Carlos & 241.389 & 41 & 1.633 .895 \\
\hline SJ do Rio Preto & 442.548 & 143 & 1.972 .835 \\
\hline SJ dos Campos & 688.597 & 15 & 795.806 \\
\hline São Paulo & 11.967 .825 & 31 & 7.791 .718 \\
\hline Sorocaba & 644.919 & 21 & 1.620 .965 \\
\hline Taubaté & 302.331 & 27 & 1.025 .535 \\
\hline \multicolumn{4}{|c|}{ Afiliadas SBT } \\
\hline Araçatuba & 192.757 & 202 & 3.000 .000 \\
\hline Jaú & 143.283 & 91 & 3.016 .399 \\
\hline \multicolumn{4}{|c|}{ Afiliada Record } \\
\hline Franca & 342.112 & 101 & 3.971 .033 \\
\hline Total & 18.058.869 & & \\
\hline
\end{tabular}

Fonte: Elaboração própria

O SBT interior, com sede em Araçatuba, cobre a região do Oeste Paulista e o seu sinal chega, inclusive, a algumas cidades de Mato Grosso que são divisa com São Paulo. Essa é a maior área de cobertura em número de cidades entre as afiadas do estado. A filiada sediada em Jaú, SBT interior, apesar de cobrir uma população próxima, reúne um número consideravelmente menor de municípios. Assim, ambas as regiões, mas principalmente a que recebe o sinal de Araçatuba são compostas por municípios em sua maioria de pequeno porte.

A Record Interior, sediada em Franca tem a maior área de cobertura entre as emissoras da região, com sinal para mais de 100 cidades, entre elas, cidades de médio porte, como Araraquara e São Carlos, e Ribeirão Preto, cidade de grande porte, segundo os critérios de população adotados pelo $\operatorname{IBGE}^{16}$. As duas últimas, sede de afiliadas de outra emissora. São essas, incluso a sede, as principais cidades cobertas pelo sinal da

${ }^{16}$ O IBGE caracteriza a rede urbana a partir dos segundos critérios: de 500 habitantes a 100 mil são cidades pequenas; entre 100 e 500 mil, cidades médias; a partir de 500 mil, cidades grandes; metrópoles acima de 1 milhão; e acima de 10 milhões as megacidades. 
afiliada, as demais cidades, a grande maioria é de pequeno porte, muitas com menos de 10 mil habitantes.

Entre as afiliadas da Rede Globo, a maior em número de cidades atingidas é a TV TEM de São José do Rio Preto, com 143 cidades, sendo a sede a maior delas e única de grande porte. A partir do mesmo critério, pode-se apontar que apenas duas outras dessa região são de médio porte, Catanduva, Birigui e Araçatuba, que também é sede de afiliada. No geral, é uma região onde a grande maioria dos municípios é de pequeno porte.

Maior área de cobertura em número de pessoas entre as afiliadas Globo é a de São Paulo, que compreende entre as maiores cidades, Guarulhos (que será discutido a seguir), São Bernardo do Campo e Osasco que tem população de 1.324.781, 816.925 e 694.844 respectivamente; EPTV Campinas, que tem Piracicaba com 391.449 e Sumaré com 265.955 como maiores cidades, além da sede; e a TV TEM Bauru, onde a área de cobertura contempla Marília e Jaú, com 232.006 e 143.283 habitantes.

Assim como no caso da afiliada do SBT em Araçatuba, onde o sinal chega a cidades de fora do estado, tem-se também o caso da EPTV Campinas, que atinge cidades do sul de Minas Gerais. Ou seja, durante as eleições, o HGPE municipal além de não ser restrito ao seu colégio eleitoral porque é transmitido para outras cidades que fazem parte da zona de cobertura de afiliadas, ele é visto também por telespectadores de outros estados.

No Estado de São Paulo, são apenas seis cidades com população entre 500 e 900 mil habitantes, grandes cidades: Sorocaba, Ribeirão Preto, São José dos Campos, Osasco, Santo André e São Bernardo do Campo. Entre elas, apenas três, como pode ser observado na tabela 02 , são sede de afiliadas, ou seja, atendem ao principal critério para que os partidos políticos tenham acesso ao HGPE.

Entre as cidades paulistas consideradas grandes, metrópoles e megacidades, Campinas, Guarulhos e São Paulo, na primeira e na última é possível o acesso ao HGPE nas emissoras abertas de TV. O caso de Guarulhos é emblemático, por se tratar de uma das maiores cidades não apenas do estado, mas do país e a cidade de maior colégio eleitoral brasileiro fora das capitais, com cerca de 900 mil eleitores.

Essa relação desproporcional entre população e disponibilidade de informação política e eleitoral via HGPE fica ainda mais evidente se observados novamente os dados da tabela 02 , sobre a população, onde 10 das 16 cidades sede de afiliadas são de porte médio, a menor delas, Itapetininga, onde, segundo o TRE (2016) cerca de 107 mil 
eleitores terãoo HGPE à disposição. Número de eleitores oito vezes menor, se comparado a Guarulhos.

Para uma melhor ilustração da relação entre número de eleitores e HGPE, a tabela abaixo lista os vinte maiores colégios eleitorais do estado de São Paulo, segundo dados do TRE para as eleições de $2016^{17}$, e o percentual dos colégios eleitorais nos municípios em relação ao colégio do estado.

Tabela 03: Cidades segundo colégio eleitoral 2016

\begin{tabular}{|c|c|c|c|}
\hline Colocação & Cidades & Colégio Eleitoral & Percentual \\
\hline 1 & São Paulo & 8.889 .638 & 27,193 \\
\hline 2 & Guarulhos & 902.135 & 2,76 \\
\hline 3 & Campinas & 822.398 & 2,516 \\
\hline 4 & São Bernardo do Campo & 612.061 & 1,872 \\
\hline 5 & Santo André & 569.864 & 1,743 \\
\hline 6 & Osasco & 566.330 & 1,732 \\
\hline 7 & São José dos Campos & 488.804 & 1,495 \\
\hline 8 & Sorocaba & 458.457 & 1,402 \\
\hline 9 & Ribeirão Preto & 435.503 & 1,332 \\
\hline 10 & Santos & 338.617 & 1,036 \\
\hline 11 & Diadema & 331.136 & 1,013 \\
\hline 12 & São José do Rio Preto & 318.606 & 0,975 \\
\hline 13 & Mauá & 303.175 & 0,927 \\
\hline 14 & Mogi das Cruzes & 296.954 & 0,908 \\
\hline 15 & Jundiaí & 290.358 & 0,888 \\
\hline 16 & Carapicuíba & 284.835 & 0,871 \\
\hline 17 & Piracicaba & 283.867 & 0,868 \\
\hline 18 & Bauru & 263.506 & 0,806 \\
\hline 19 & São Vicente & 256.517 & 0,785 \\
\hline 20 & Barueri & 245.036 & 0,75 \\
\hline \multicolumn{2}{|l|}{ Total } & 16.957.797 & 51,872 \\
\hline
\end{tabular}

Fonte: Elaboração própria

Entre os 20 maiores colégios eleitorais de São Paulo, em apenas nove cidades é garantido aos partidos o acesso à propaganda eleitoral televisionada. As demais cidades sede de afiliadas que não estão entre os municípios mais populosos do estado são:

17 Para mais informações sobre estatísticas do eleitorado para as eleições de 2016, acessar: http://www.tse.jus.br/eleitor/estatisticas-de-eleitorado/consulta-quantitativo. Acesso em 04 de novembro de 2016. 
Tabela 04: Cidades sede de afiliadas segundo colégio eleitoral 2016

\begin{tabular}{r|l|r|r}
\hline \multicolumn{1}{l|}{ Colocação } & Cidades & Colégio Eleitoral & Percentual \\
\hline 21 & Franca & 231.967 & 0,71 \\
\hline 24 & Taubaté & 222.855 & 0,68 \\
\hline 30 & São Carlos & 179.770 & 0,55 \\
\hline 32 & Presidente Prudente & 169.366 & 0,51 \\
\hline 42 & Araçatuba & 142.502 & 0,43 \\
\hline 52 & Itapetininga & 107.013 & 0,32 \\
\hline 54 & Jau & 98.961 & 0,30 \\
\hline \multicolumn{2}{r}{}
\end{tabular}

Fonte: Elaboração própria

A estimativa de colégio eleitoral do estado de São Paulo, segundo o TRE, é de 32.690.511 eleitores. Entretanto, apenas 13.464 .917 ou 41,16\% dos desses, residem em municípios sede de afiliadas de emissoras de TV aberta, principal critério para que seja viabilizado aos partidos políticos o acesso à propaganda política eleitoral. Isso representa menos da metade dos eleitores paulistas. Ou seja, a maioria dos eleitores no estado de São Paulo não tem acesso à propaganda eleitoral na TV.

Para avaliar o segundo critério estabelecido pelo TSE, segundo o qual em cidades com mais de 200 mil eleitores os partidos podem requerer espaço na TV, atentase aos dados das duas últimas tabelas. Na terceira, pode ser observado que entre as vinte cidades de maior colégio eleitoral do Estado, onze podem solicitar junto ao tribunal o acesso ao HGPE, o que representa 11,2\% do eleitorado paulista. Em contraponto, cinco das cidades sede de afiliadas, não atendem ao critério do tamanho do colégio eleitoral: São Carlos, Presidente Prudente, Araçatuba, Itapetininga e Jau.

Ainda sobre os critérios estabelecidos pelo TSE, a exigência de consenso entre partidos dos municípios que tem interesse em transmitir a sua propaganda e as emissoras de TV, torna o processo ainda mais complexo. Soma-se a isso o conflito de interesses entre candidatos da mesma legenda em municípios vizinhos e das emissoras de TV em relação à audiência, uma vez que transmitindo a propaganda eleitoral de uma cidade com mais eleitores, a tendência é um maior público.

Para melhor exemplificar, a cidade com maior número de emissoras é a capital paulista. São sete as emissoras concessionadas na cidade. Assim, pelos critérios do TSE sete cidades com mais de 200 mil eleitores poderiam requerer o direito de acesso à veiculação de propaganda eleitoral, por meio de consenso entre partidos e emissoras, ou 
a partir da realização de um sorteio. Entre a região da capital paulista, são pelo menos nove cidades ${ }^{18}$ com colégio eleitoral suficiente para atender à regra estabelecida do TSE. Fica clara a impossibilidade do tribunal de atender aos seus próprios critérios.

Além disso, o TSE determina que o plano de mídia seja estabelecido a partir de 15 de agosto do ano eleitoral. Ou seja, menos de um mês antes do início da veiculação da propaganda eleitoral na televisão. Como já argumentado nas seções anteriores, o fator "tempo" é essencial para a organização de uma campanha eleitoral, principalmente com acesso à TV. Assim, ainda que seja "viável", que haja consenso entre os partidos de cidades vizinhas, e que esses consigam o direito à transmissão da propaganda eleitoral a partir de emissoras sediadas em outros municípios, dificilmente o uso da TV poderia ser instrumental, uma vez que exige planejamento profissional e tempo.

\section{Considerações finais}

Este trabalho teve como principal objetivo indicar em quais municípios do estado de São Paulo há possibilidade dos partidos veicularem a sua propaganda eleitoral. Para tanto, foi mobilizada primeiro, a legislação e as regras específicas pelas quais esse direito é garantido e, em seguida, apresentou-se os dados sobre os atlas de concessão e cobertura das emissoras de TV aberta estabelecidas nos municípios paulistas, do qual depende a existência do HGPE nos municípios locais.

É sabida a importância da campanha eleitoral mediada pela televisão como uma das mais importantes variáveis para a o voto. Entretanto, a primeira consideração que se faz a partir dos dados apresentados é que a veiculação da propaganda eleitoral nos municípios brasileiros depende, primeiro, de critérios técnicos, não de variáveis políticas. E ainda, quando a legislação prevê que esses critérios sejam considerados, tal quando se refere à possibilidade de que em cidades com mais de 200 mil eleitores, os partidos exijam espaço na TV, fica clara a complexidade desse processo.

Resultado disso é que em cidades com colégios eleitorais significativos, como o caso da cidade de Guarulhos, mas não apenas, os eleitores são privados dessa fonte de informação política. Enquanto que, em municípios com colégio muito menos representativo e que, inclusive, não atendem ao critério estabelecido pelo TSE em

\footnotetext{
${ }^{18}$ São elas: Barueri, Carapicuíba, Diadema, Guarulhos, Mauá, Osasco, Santo André, São Bernardo do Campo e Taboão da Serra.
} 
relação ao número de eleitores, há propaganda eleitoral televisionada, o que acontece em pelo menos cinco das cidades sede de emissoras filiadas.

O segundo importante apontamento é a previsão de que para as eleições municipais de 2016, mais da metade dos eleitores paulistas, 58,84\%, não terá acesso à propaganda eleitoral televisionada, restrita a pelo menos 16 municípios. Esse dado se torna ainda mais relevante se considerado que, as emissoras de TV aberta concentram maior número de afiliadas concessionadas no estado de São Paulo, ou seja, para outros estados, esse percentual pode ser ainda maior.

As propagandas eleitorais dos municípios são as únicas no Brasil em que o número de pessoas atingidas ultrapassa o colégio eleitoral para o qual são formuladas. Podendo, inclusive, chegar a cidades de outros estados. Por exemplo, a propaganda eleitoral da cidade de São Paulo que é feita para quase nove milhões de eleitores, mas atinge cerca de 20 milhões de pessoas; ou Campinas, cujo colégio é composto por 822 mil eleitores, mas a propaganda eleitoral chega a quase quatro milhões e meio de pessoas.

Uma das possíveis consequências disso é que, em municípios que fazem parte da zona de cobertura de emissoras concessionadas em cidades vizinhas, o voto dos eleitores pode ser influenciado pela propaganda eleitoral dessas cidades, principalmente se os mesmos partidos disputarem as eleições nos dois locais e também se houver a presença de líderes partidários influentes nessas campanhas. Além disso, até as eleições de 2012, os candidatos a prefeito contavam com mais tempo de TV se comparados aos candidatos aos demais cargos executivos, ao passo que, contam com menos dinheiro para financiar as atividades de campanha, inclusive, a produção de conteúdo para a TV, que é um dos fatores encarecedores dessas campanhas.

Ainda, é possível argumentar que o número de eleitores contemplados pela propaganda eleitoral nos municípios paulistas não é abrangente, uma vez que a grande maioria assiste na TV à propaganda das cidades vizinhas. Decorrente disso, que o HGPE não tem a mesma importância durante as eleições locais, se comparada à sua centralidade para partidos e candidatos que disputam cargos durante as eleições gerais. Dessa forma, esses partidos apoiam-se em outros meios para organizar a comunicação de suas campanhas. 


\section{Referências}

ALBUQUERQUE, A. Os spots políticos: Americanização da Propaganda política brasileira. In: Encontro anual da associação nacional de pós-graduação e pesquisa em ciências sociais, 22, 1997. ANAIS. CAXAMBU (MG). v. 1. p. 1-19, 1997.

Aqui você vê a verdade na tevê: A propaganda política na televisão.

Niterói: MCII. 1999.

ALDÉ, Alessandra; DIAS, Heloísa. Intervalo surpresa: spots eleitorais na campanha municipal de 1996. Comunicação \& Política, n.s, v.5, no. 1, pp. 83-100. 1997.

ALVES, M. Partidos políticos e campanhas profissionais: As eleições municipais de Sorocaba em 2012. In. VI Congresso da Associação Brasileira de Pesquisadores em Comunicação Política (COMPOLÍTICA), 2015, Anais, Rio de Janeiro, PUC-RIO, 2015. AZEVEDO, Fernando Antônio. A mídia, a democracia de público e a modernização das campanhas eleitorais no Brasil. Teoria \& Pesquisa, São Carlos - SP, v. 36-37, p. 07-20, 2001.

Mídia e democracia no Brasil: relações entre o sistema de mídia e o sistema político. Opinião Pública, Campinas, SP, v. XII, p. 88-113, 2006.

Espaço público, mídia e modernização das campanhas eleitorais no Brasil. In: REUNIÃO ANUAL DA COMPÓS, 7., São Paulo, 1998.

ALDÉ, Alessandra; DIAS, Heloísa. Intervalo-surpresa: spots eleitorais na campanha municipal de 1996. Texto apresentado no VI Encontro Anual da COMPÓS. São Leopoldo (RS), 1997.

BRAGA, Sergio. O uso das mídias sociais é um bom preditor do sucesso eleitoral dos candidatos? Uma análise das campanhas on-line dos vereadores das capitais das regiões sul, sudeste, e nordeste do Brasil no pleito de outubro de 2012. Revista Política Hoje. v. 22, p. 125-148, 2014.

; NICOLÁS, Alejandra; BECHER, André Roberto. Clientelismo, internet e voto: personalismo e transferência de recursos nas campanhas online para vereador nas eleições de outubro de 2008 no Brasil. Opinião Pública, vol.19 no.1 Campinas jun. 2013.

BORBA, F. A Influência das Campanhas nas Eleições Presidenciais Brasileiras. Civitas, Porto Alegre, v. 08, 2008, p. 300-322.

CANEL, Maria José. Comunicación política: um guía para su estudo y práctica. Madri, Técnos, 1999. 
DANTAS, H. O horário eleitoral gratuito na televisão e o padrão das coligações em eleições majoritárias municipais. Leviathan, Cadernos de Pesquisa Política, n. 5, pp.1$14,2012$.

FARRELL, David M. Political parties in a changing campaign environment. In. CROTTY, Willian; KATZ, Richard S. Handbook of party politics. Sage Publication ltd, 2009.

FIGUEIREDO, Marcus; ALDÉ, Alessandra; DIAS, Heloísa; JORGE, Vladimyr. Estratégias de persuasão eleitoral: uma proposta metodológica para o estudo da propaganda eleitoral. Opinião Pública, Campinas, vol. IV, no 3, Novembro, 1997, p.182-203.

GOMES, W. S. Opinião pública política hoje: Uma investigação preliminar. In: Antonio Hohfeldt. (Org.). Práticas Mediáticas e Espaço Público. Porto Alegre: Editora da PUC/RS, 2001, v. 1, p. 61-82.

IASULAITIS, S. Internet e Propaganda Política no Brasil: limites e possibilidades. Estudos de Sociologia (São Paulo). v. 23, p. 153-172. 2008.

Modalidades de participação política em websites eleitorais: uma análise de fóruns de discussão com uma proposta metodológica. In: MARQUES, F.J; AGGIO, C.; SAMPAIO, R.. (Org.). Do clique à urna: Internet, Redes Sociais e Eleições no Brasil. 1ed. Salvador: EDUFBA - Editora da Universidade Federal da Bahia, 2013, v. , p. 183-214.

JARDIM, M. Palanque eletrônico em eleições locais: aspectos do acesso dos municípios ao HGPE na televisão. Revista Sociologia Política, Curitiba, 22, p 45-58, jun. 2004.

MANCINI, P.; SWANSON, D. L. Politics, Media and Modern Democracy: an International Study of Innovations in Electoral Campaigning and their Consequences. Westport, London: Praeger, 1996.

MASSUCHIN, M; Campos-Domínguez, Eva. Debate online y campaña electoral en Brasil: Los comentarios de los electores em las webs de candidatos en 2014. Em Debate, Belo Horizonte, v.8, n.4, p.18-32, jun. 2016.

LAVAREDA, A; TELLES, M. (Orgs) A lógica das eleições municipais. Rio de Janeiro, FGV Editora, 2016.

. (Orgs.). Como o Eleitor Escolhe seu Prefeito. 1ed. Rio de Janeiro: FGV Editora, 2011.

MANIN, Bernard. A democracia do público reconsiderada. In Novos Estudos Cebrap, no 97, São Paulo. 2013. 115-127. 
As metamorfoses do governo representativo. Revista brasileira de Ciências Sociais, São Paulo, ano 10, n. 29, 1995.

MAZZOLENI, G. La comunicación política. Alianza Editorial. Madrid, 2010.

MACCOMBS, Maxwell. A teoria da agenda - a mídia e a opinião pública. Petrópolis, Vozes, 2009.

NORRIS, P. The Virtuous Circle - Political Communication In Postindustrial Societies. New York: Oxford University Press. 2000.

PANKE, Luciana; CERVI, Emerson U. (org.) Eleições nas capitais brasileiras em 2012: um estudo sobre o HGPE em disputas municipais. Edição 1. E-book Versão PDF, 2013.

PENTEADO, C. L. C. Facebook e a campanha eleitoral digital. Em Debate, Belo Horizonte, v. 4, p. 41-53, 2012.

RIBEIRO, P. Campanhas Eleitorais em sociedades midiáticas: articulando e revisando conceitos. Rev. Sociol. Polít., Curitiba, 22, jun. 2004, p. $25-43$.

RUBIM, A. Novas configurações das eleições na idade mídia. In. Opinião Pública. vol.7. n. 2 Campinas Nov. 2001.

PORTO, M. Televisão e voto: a eleição de 1992 para prefeito de São Paulo. Opinião Pública, Campinas, vol. IV, no 1, Abril, 1996, p.65-81.

VEIGA, Luciana. Em busca das razões do voto: o uso que o eleitor faz da propaganda política. Contra campo, 1182-208, V. 7 n.0, 2002.

Recebido em 8 de agosto de 2016.

Aprovado em 28 de setembro de 2016. 